\title{
Population Estimation using Land-Use Change Data from Multi-Sensor Images in Maha Sarakham Province, Thailand
}

\author{
Suwanlee, S. R.* and Som-ard, J. \\ Department of Geography, Geoinformatics and Resources Management Research Unit, Faculty of \\ Humanities and Social Sciences, Mahasarakham University, Maha Sarakham Province, 44150, Thailand \\ E-mail: savittri.s@msu.ac.th, jaturong.s@msu.ac.th \\ *Correspondance Author \\ DOI: https://doi.org/10.52939/ijg.v17i3.1901
}

\begin{abstract}
Land-use changes surrounding Mahasarakham University in Thailand were investigated using multi-sensor images from 2002 and 2019. This study used aerial photographs and Landsat-7 satellite images captured in 2002, and aerial photographs from an unmanned aerial vehicle and Sentinel-2A data observed in 2019.Visual image interpretation (VII), object-based image analysis (OBIA), and random forest $(R F)$ methods were applied to classify building areas from the multi-sensor images. Population was estimated using buildings and fieldsurvey data, and population samples. The samples were obtained by point-, pixel-, and area-based methods. The different population estimation approaches were then compared with the actual population based on field surveys. VII yielded accuracies of 97\% in 2002 and 97.5\% in 2019. Built-up extraction using RF yielded accuracies of 86.55 and $90.76 \%$, whereas OBIA was 76.47 and $82.35 \%$, indicating a transformation in the land use from paddy fields to urban and residential areas. The area-based method were highly efficient in $2002\left(r^{2}\right.$ $=0.92)$ and $2019\left(r^{2}=0.93\right)$. The proposed area-based method provides more accurate population estimates than existing methods, with accuracies considered to be comparable to those of field data.
\end{abstract}

\section{Introduction}

Maha Sarakham Province is centrally located in the north-eastern part of Thailand. Under the Government of Thailand's Strategic Plan for Provincial Development, Promotion, and Development of Educational Management, Maha Sarakham has become a centre of education in Thailand (Department of Provincial Administration, 2019). In particular, the Mahasarakham University area has expanded rapidly in recent years, which has caused significant land-use changes, especially the transformation of agricultural land into urban and residential areas (Som-ard et al., 2018 and Prasanchum and Kangrang, 2017). This process is referred to as studentification and is considered an aimless expansion that lacks a clear development plan (Chaichakan et al., 2017).

Population estimations are essential for driving development and formulating a country's policies in terms of population, economy, society, and public health. The Office of the National Economic and Social Development Board coordinates population estimation activities, and data collection occurs every ten years with the most recent collection in 2010 (Office of the Nation Economic and Social
Development Board, 2007). As data collection is expensive, it is not possible to collect data every year. Therefore, given the rapid pace of development, the data used for planning may not be up to date (Prasartkul et al., 2016 and Suwanlee and Som-ard, 2020). The utilization of remote sensing techniques with satellite image data from Landsat-7 ETM+, with 8 bands, and Sentinel-2A MSI, with 13 spectral bands, provide valuable information for a wide range of land monitoring activities. Data from both satellites have proved to be an important tool to extract the surface characteristics of Earth, dynamics over time, and update population data based on analyses of land use changes (Phiri and Morgenroth, 2017, Immitzer et al., 2016 and Lu et al., 2010). Using census data, which includes population count, population distribution, and population density, highly detailed satellite images can be classified using aerial interpolation (Ma et al., 2017 and $\mathrm{Ye}$ et al., 2019). In contrast, estimations with other data include land-use networks and communication networks (Goodchild et al., 1993, Páez and Scott, 2004, Reibel and Agrawal, 2007 and Wu et al., 2005). Various studies 
have explored the effectiveness of using these two techniques to determine the relationships among population, city area, land use, building and residence type, physical characteristics, economy, society, and building heights (Batista e Silva et al., 2013, Kumar et al., 2018 and Johnson and Xie, 2013). In addition to evaluations of classification performances using standard measures of accuracy (such as the overall accuracy and kappa coefficient), individual measures of accuracy, such as producer's accuracy, user's accuracy, and conditional kappa, have been used, resulting in accuracies of approximately $70-90 \%$ (Bai et al., 2018, Karume et al., 2017 and Lloyd et al., 2017).

There is currently a paucity of in-depth investigations regarding the use of population estimation techniques. These types of studies can be used to investigate changes in the area around universities in Thailand using satellite images from different years in combination with other data. This study investigated land-use and habitat extraction changes surrounding Mahasarakham University using multi-sensor data collected at different times. The potential of the different population estimation techniques and the reliability of the data, including the building area, population, and data collected from the field, were analysed. The population estimation technique recommended in this study may be beneficial for use in spatial decision making, owing to its potential in the cost-effective and rapid collection of census data at the sub-district municipality level. The results provide a basis for the analysis of land-use changes surrounding a university town and can be used to identify policies and plans for future development. Therefore, this study provides guidelines for identifying a suitable and reliable population estimation technique using accurate criteria. Moreover, this approach was examined for appropriateness and approved by the Mahasarakham University Ethics Committee on Human Research (No. 114/2019).

\section{Methodology and Data}

\subsection{Study Area}

Mahasarakham University is situated within Maha Sarakham City. The city is located in the heart of Northeast Thailand and is a centre for education. The study area covers an area of approximately 27 $\mathrm{km}^{2}$. The population, as obtained from the National Statistical Office, was 7,558 in 2002 and 40,346 in 2019 (Department of Provincial Administration, 2019). Maha Sarakham City has two communities, i.e., Tha Khong Yang and Khamriang, and a population density of 1,485 persons $/ \mathrm{km}^{2}$. Expansion of the university has occurred in the Khamriang
Sub-district in the Kantarawichai District, which has an area of approximately $2.08 \mathrm{~km}^{2}$. The total enrolment of new students in 1995 was 3,078, and the student population has continuously increased since that time, with 38,182 students enrolled in 2002 and 75,162 in 2019 (Mahasarakham University, 2019) (Figure 1). Land-use patterns of settlement occur along the riverside of the Chi River. Most of the agriculture area depends on natural resources as the fundamentals for their quality of life. Most of the residents grow rice and other plants. However, this situation has changed with the rapid growth of the university. Education has been elevated and expanded throughout the region, which has resulted in land-use changes from agriculture to building areas. Members inside and outside of the local community have accordingly changed their occupations from agriculture to commerce.

\subsection{Data Acquisition and Preparation}

Data for classifying land-use changes between 2002 and 2019 using multiple remotely sensed images acquired at different times indicated the geographical features at different map scales. In 2002, aerial photographs were observed on 21 January at a $10-\mathrm{cm}$ spatial resolution obtained from the Royal Thai Survey Department, which were used to adjust the histogram or value of the image spot colour for strong and clear images (Brooner, 1976). Aerial photographs obtained from an unmanned aerial vehicle (UAV) were used for picture editing, along with those obtained from Google Earth. UAV images were captured during a flight survey in May 2019 using a DJI Phantom 3 professional drone flying at a height of $120 \mathrm{~m}$ with $40 \%$ side overlap and $60 \%$ front overlap (Wayumba et al., 2017). The processed UAV image had a $2-\mathrm{cm}$ spatial resolution with RGB spectral bands. Data from the aerial photographs were processed by geometric correction using sixteen ground control points (GCPs); the GCPs were referenced with similar objects from the UAV and Google Earth images. The distribution of the GCPs are sufficient as a reference in the study area. The image data were clearly visible and of sufficient quality for extracting surface information via the visual image interpretation (VII) technique (Silva et al., 2018 and Stöcker et al., 2019).

Satellite image data from Landsat-7 ETM+ (Path: 128, Row: 49) were recorded on 18 February 2002 using bands 1-5, and 7. Data from the Sentinel-2A MSI were acquired on 26 October 2019 using bands $2,3,4,5,6,7,8,8 \mathrm{~A}, 11$, and 12 . 


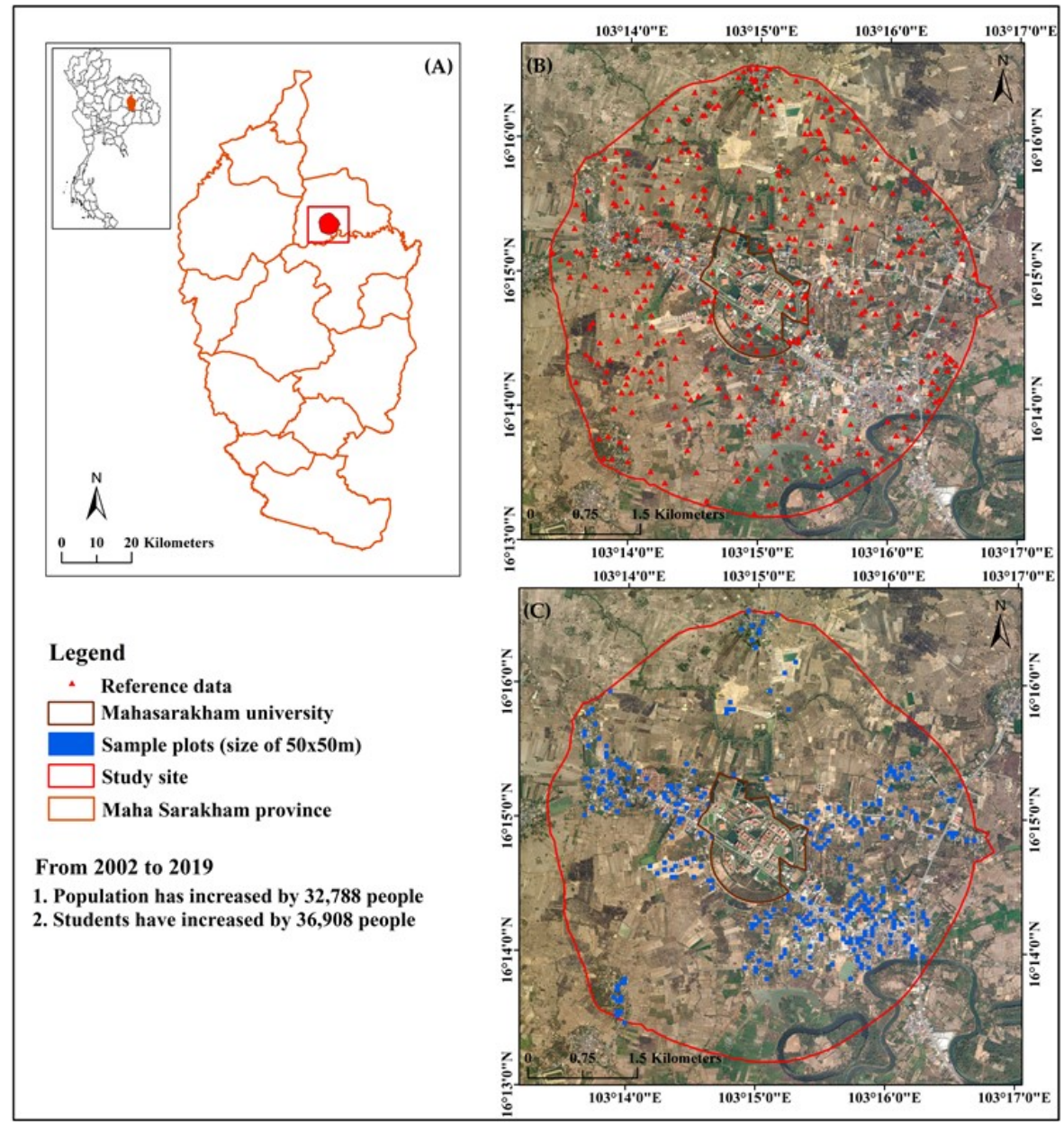

Figure 1: Area of study. (A) The study area is located $2 \mathrm{~km}$ from the centre of Mahasarakham University in north-eastern Thailand. (B) and (C) show the perimeter of the study site (red line), the location of the reference data (B) (red triangle), and the sample plots (C). (B) and (C) show the background satellite images that were captured on 21 December 2019, which are available on Google Earth

Image data with cloud cover conditions $<10 \%$ and conditions suitable for the level of visual interpretation required for this study were selected. The obtained images were corrected and adjusted for atmospheric effects by the U.S. Geological Survey and European Space Agency (Munyati, 2017). Small amounts of cloud cover were deleted using Fmask for the Landsat-7 ETM+ images and the dense cloud mask was deleted for the Sentinel2A MSI images (Zhu et al., 2016). Landsat-7 ETM+ and Sentinel-2A images were resampled at a $10 \times 10 \mathrm{~m}$ resolution, which provided more details, as listed in Table 1. Moreover, the Normalised Difference Building Index (NDBI) index indicates built-up areas (Hu et al., 2016 and Zha et al. 2003). This study calculated and used the NDBI to classify buildings areas for population estimation. Maps regarding land use and building types, generated by the Department of Public Works and Town \& Country Planning, and a topographic map from the Department of Military Maps, at a scale of 1 : 50,000 , were also obtained. To verify the accuracy and classify land-use, data collected from the field were used in combination with these maps to assist in identifying sample points in the study area. We collected ground-truth data using GPS and selected sample points using a random stratified sampling approach (Brooner, 1976) in QGIS 8.3.1. A handheld GPS was used for ground observations (Bangira, 2019). In total, data were collected from 400 sampling points (Figure 1A). The VII and OBIA classification methods were applied using data from 400 points for accuracy assessment; classification using the RF method required 280 points $(70 \%)$ for training data and 120 points $(30 \%)$ for accuracy verification. 
Table 1: Sensor images used with the classifier methods

\begin{tabular}{|c|c|c|c|}
\hline Data & $\begin{array}{l}\text { Visual image } \\
\text { interpretation }\end{array}$ & \multicolumn{2}{|c|}{$\begin{array}{c}\text { Object-based image analysis (OBIA) and } \\
\text { Random forest (RF) }\end{array}$} \\
\hline Sensor images & $\begin{array}{l}\text { Aerial Photograph } \\
2002 \text { and } \\
\text { UAV } 2019\end{array}$ & Landsat-7 ETM+ 2002 & Sentinel-2A MSI 2019 \\
\hline Spectral band & Red, green, blue & $\begin{array}{l}\text { Band 1-Blue } \\
\text { Band 2-Green } \\
\text { Band 3-Red } \\
\text { Band 4-Near Infrared (NIR) } \\
\text { Band 5-SWIR 1 } \\
\text { Band 6-Thermal } \\
\text { Band 7-SWIR 2 } \\
\text { Band 8-Panchromatic }\end{array}$ & $\begin{array}{c}\text { Band 1-Coastal aerosol } \\
\text { Band 2-Blue } \\
\text { Band 3-Green } \\
\text { Band 4-Red } \\
\text { Band 5-Vegetation red edge 1 } \\
\text { Band 6-Vegetation red edge 2 } \\
\text { Band 7-Vegetation red edge 3 } \\
\text { Band 8-Near Infrared (NIR) } \\
\text { Band 8A-Vegetation red edge } 4 \\
\text { Band 9-Water vapour } \\
\text { Band 10-SWIR-Cirrius } \\
\text { Band 11-SWIR 1 } \\
\text { Band 12-SWIR 2 }\end{array}$ \\
\hline $\begin{array}{l}\text { Spatial } \\
\text { resolution (m) }\end{array}$ & 0.2 & 15,30 , and 60 & 10,20, and 60 \\
\hline
\end{tabular}

The same validation set was further used within all classification products to ensure high classification accuracy, despite the wide variety of land-use ratios within the grid cells. The generalisation capability of these products is of particular importance with small training samples (Chen et al., 2017). Thus, a sample point for ensemble classification via machine learning was defined. However, from 15 November to 27 December 2019, actual population data were also collected via field surveys using interview forms; the surveys were based on different grid sizes and population characteristics (Figure 1C).

\subsection{Image Classification and Land Change Detection}

UAV technology provides new mapping property boundaries for land registration and is highly efficient in extracting high levels of land use classes (Wayumba et al., 2017 and Guo et al., 2018). This study explored aerial remote sensing data to extract land-use information in a complex area. Aerial photographs captured in 2002 and photographs taken by the UAV in 2019 were analysed using the VII method. We interpreted and digitized land-use maps using QGIS 8.3.1. In addition, we used novel, advanced, and digitizing tools (i.e., construction, parallel, and perpendicular modes) to determine the shapes or angles of robust roofs and built-up areas. The principles used for interpretation included the 11 land-use classes defined by the Thailand Land Development Department (Land Development Department, 1977, 2016). Object information from satellite images was obtained using the multi- resolution segmentation method, which involves three parameters, i.e., scale and shape combinations produce the highest classification accuracies, while the compactness parameter has a minimal effect on the construction of image objects in the eCognition trail (Blaschke, 2010). Hence, compactness can be set to a constant value in image segmentation (Blaschke, 2010 and Kavzoglu and Yildiz, 2014). We tested numerous parameter sets based on the field surveys and our previous experience. In addition, the outputs of segmentation were visually measured using a trial-and-error approach (Immitzer et al., 2016). Thus, the best rule parameters were 12 , 0.3 , and 0.7 (scale, shape, and compactness) for Landsat-7 ETM+ in 2002 while Sentinel-2A MSI in 2019 was defined as $15,0.3$, and 0.5 , respectively. The NDBI index was used to determine the average pixel value of the building index per object. The classification technique was used to identify the homogeneity of objects according to the land-use type using OBIA. The hierarchy classifier used the same principles as the membership function, which applies the principles of fundamental statistics (i.e., maximum, minimum, and mean) for regional values for effective classification (Yang and $\mathrm{He}, 2010$ ). Thus, two types of land uses were extracted: building and non-building areas (Phiri and Morgenroth, 2017).

The RF is an ensemble algorithm of decision trees that produces a prediction for classification and regression. This classifier has recently become popular owing to its high classification accuracy (Breiman, 2001). RF is used to classify land use and examine the relationships between the factors of 
each band through a machine learning algorithm, with the use of a decision tree and learning system from feature values of the training data. The RF approach measures an unbiased interval of the generalization error, referred to as "out-of-bag" (OOB) samples. RF also provides the input features importance, referred to as the Mean Decrease in Accuracy (MDA), which is used for feature ranking (Breiman, 2001 and Cutler et al., 2012). We determined and classified built-up areas using the randomforest package in the $\mathrm{R} 3.6 .2$ software. In this study, a model set was built based on training data collected in the field. Land-use type attributes of the samples were defined using the training data (Liaw and Wiener, 2002); thus, this study separated 280 sample points $(70 \%)$ for the training model and 120 points $(30 \%)$ to validate the classification results. Next, the proposed model was applied to classify the satellite images based on the sample area derived from the suitable model. The suitable model was produced by the decision tree, along with the learning principles of the system from the sample area, which was used to identify the feature space of the spectral information from the Landsat-7 ETM+ and Sentinel-2A MSI bands. NDBI was also applied to classify built-up area. The important feature was used to extract the object and classify buildings. We chose the defaults values of the $n$ Tree parameter for 500 trees and Mtry was set to the square root of the total number of input variables (Immitzer et al., 2019 and Pflugmacher et al., 2019).

To verify the accuracy and effectiveness of the land-use classification of each technique, the confusion matrix and kappa concordance were used in the calculations (Congalton and Green, 1999). Moreover, land-use maps from 2002 and 2019 were used to compare the results through visual interpretation for agreement (Hua et al., 2012). Land-use changes were determined using the proposed land-use maps from the VII method and the 'from-to' change detection method ( $\mathrm{Lu}$ et al., 2014). We also analysed the detailed changes from
2002 to 2019 based on this approach.

\subsection{Population Estimates via Analysis of Built-Up Data}

Although many studies have estimated population using statistical models with high remote sensing imagery, population dwellings, and geospatial data, previous methods are either very expensive, have several input scales, or are time-consuming (Alahmadi et al., 2013, 2014, Dong et al., 2010, Guo et al., 2017, Mossoux et al., 2018 and Stevens et al., 2015). Thus, in this study, we investigated a novel estimation method in areas with diversified land-uses to provide fast, reliable, and economical results based on remote sensing data. We tested the accuracy of the population estimation using point-, pixel-, and area-based methods in the urban area surrounding the university town. Moreover, we used up-to-date information on the cost-effectiveness of multi-sensor data (i.e., new UAV and Sentinel-2A imagery) and ground data for rapid and efficient population estimation.

The built-up density map and actual population per sample grid were used for the point-based approach. Grids of dimensions 50, 100, 200, and $300 \mathrm{~m}^{2}$ were created over the entire study area for both years, as shown in Figure 2 and listed in Table 2. The built-up areas were classified using VII and converted to point data by placing them on the grid as a built-up density map. This analysis was performed to extract the number of built-up areas into the grid size using the zonal statistics tool in QGIS for generating the building density and grid density data. The sample grid was randomly defined for the collected population data from ground surveys. This study used the stratified random sampling technique based on built-up density maps to obtain data from the ground survey in 2002 to determine the accuracy of the example grid: example grids of $227\left(50 \mathrm{~m}^{2}\right), 153\left(100 \mathrm{~m}^{2}\right), 84$ $\left(200 \mathrm{~m}^{2}\right)$, and $61\left(300 \mathrm{~m}^{2}\right)$ plots were used.
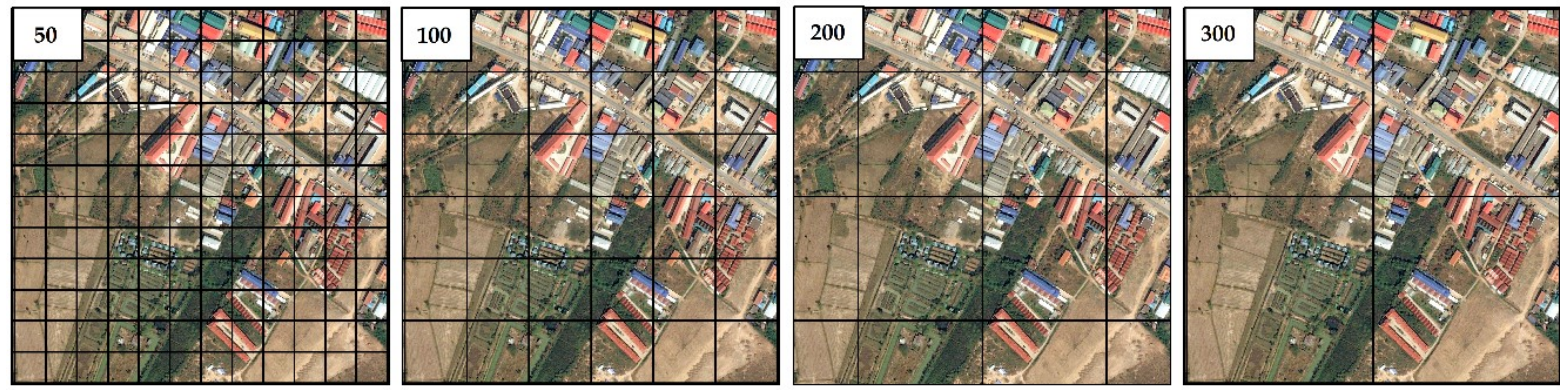

Figure 2: Examples of the use of the 50,100, 200, and $300 \mathrm{~m}^{2}$ grids 
Table 2: General characteristics of the three types of population estimation using remote sensing techniques

\begin{tabular}{|c|c|c|c|}
\hline & Pointed-based & Pixel-based & Area-based \\
\hline Year(s) of estimation & \multicolumn{3}{|c|}{2002,2019} \\
\hline Population in 2002 & \multicolumn{3}{|c|}{7,558} \\
\hline Population in 2019 & \multicolumn{3}{|c|}{43,406} \\
\hline Land-use technique & VII & OBIA/RF & VII \\
\hline Modelled input & \multicolumn{3}{|c|}{ Land use of built-up areas } \\
\hline Grid samples & \multicolumn{2}{|c|}{$50,100,200,300$} & $\begin{array}{l}\text { Built-up area per } \\
\text { building use }\end{array}$ \\
\hline Accuracy assessment & \multicolumn{3}{|c|}{$\mathrm{R}^{2}$ and RMSE } \\
\hline
\end{tabular}

Data collection in 2019 comprised 331, 266, 171, and 119 plots. The aforementioned grid sizes were designed to cover residences (Figure 2) using population data collected during a field survey from November-December 2019 using an interview form. This allowed for the comparison of the number and location of buildings together with data on the average actual population per area of each grid square. The next step involved reclassifying eight groups from different densities of built-up locations (the area of built-up locations per grid) and the average population per example grid. Finally, data from the samples were analysed to assess the population across all grid squares in the entire study area, defined as follows (Ye et al., 2019):

$$
\begin{gathered}
P_{c}=\frac{F}{G} \text {, and } \\
P p e=\sum_{c=1}^{n} G_{c} \times P_{c}
\end{gathered}
$$

Equation 1

Equation 2

where $P p e$ is the population of the total grid; ${ }^{G_{c}}$ is the area of the total grid in eight groups; $G$ is the number of buildings per example grid in each group; $P_{c}$ is the average population of the example grid in each group; and $F$ is the population per area of the example grid.

A pixel-based method was conducted using the built-up map produced from the classification of the built-up area with the high accurate results. The grid maps were used to extract data on the number of built-up pixels from the built-up areas to map the built-up density. The example grid data from 2002 and 2019 (Figure 2) were used to collect population data from the ground surveys. This was then used to reclassify the areas of different built-up area densities and to calculate the actual average population in each group. These rule-based groups were then used to estimate the total population across the entire grid-covered study area as follows:

$$
P i e=\sum_{c=1}^{n} P i_{c} \times P_{c}
$$

Equation 3

where $P i e$ is the population per total area; $P i_{c}$ is the number of grid squares in each built-up area density group; and $P_{c}$ is the group of population density per total grid squares in each group.

In addition, the area-based method involved the interpretation of land-use and the visual extraction of the building types. For population estimation, we classified seven types of built-up areas (including detached houses, row houses, hotels, dormitories, commercial, townhouses, and other residences) according to the structure type and different sizes of the built-up areas. This method used actual population data from 40 sample built-up areas for each type within a total of 280 buildings from the estimation surveys. Finally, the actual population data for different types of built-up areas were calculated and the relationship between population data and built-up area was determined using an estimate of the population, which was calculated via simple linear regression analyses (Alahmadi et al., 2013), as follows:

$$
Y=a \pm b x
$$

Equation 4

where $Y$ is the population per building; $\mathrm{x}$ is the built-up area; $a$ is the y intercept or $\mathrm{y}$ when $\mathrm{x}=0$ (y intercept), and $b$ is the regression coefficient or change in $\mathrm{y}$ when $\mathrm{x}$ is one unit different.

Estimating the population from the size of the residential building area in each group yielded different results based on Equation (4). Therefore, the population obtained from each group estimation was combined to estimate the total population, as follows: 


$$
\text { Tpe }=\sum_{c=1}^{n} Y_{p_{c}}
$$

Equation 5

where Tpe is the population per total area and $Y p_{c}$ is the total population predicted in each group.

Different methods of population estimation provided different estimation results; therefore, to find the best method and obtain the optimal population estimation, basic statistical measurements were applied. This study collected 60 sample data to validate the results via the field survey; these data were also estimated from the population. Two statistical measurements were used, i.e., the coefficient of determination $\left(\mathrm{R}^{2}\right)$ and the root mean square error (RMSE) (Bai et al., 2018 and $\mathrm{Lu}$ et al., 2010). These statistical indices were used to calculate the spatial error and determine the most appropriate estimation technique.

\section{Results}

\subsection{Land-Use Changes from 2002 to 2019}

The classification of land-use based on visual inspections in 2002 and 2019 yielded total accuracies of 97 and $97.5 \%$, respectively, using a kappa accuracy of 1 . The User's accuracies (UAs) were 96.81 and $95.50 \%$, respectively, whereas the producer's accuracies (PAs) were 98.45 and $99.45 \%$, respectively. These results yielded a high level of accuracy, thereby indicating that the methods are suitable for classifying land-use. Figure 3 depicts the land-use changes surrounding Mahasarakham University from 2002 to 2019.
In 2019, most of the residential areas were at a distance of approximately $1 \mathrm{~km}$ from the university. Members both inside and outside the local community changed their occupations from agriculture to commerce in response to the needs of the growing population in the vicinity of the university. The field data were examined together with the VII data from 2002 to 2019 (Table 3). Areas with the highest land-use classification accuracy were agricultural, government, building, and other areas. Of the 11 land-use types, those that had overall increases in land-use changes were residential $(10.81 \%)$, building areas $(7.35 \%)$, and water bodies (i.e., rivers and streams) (1.36\%). Land-use types that experienced a decrease in area were paddy fields and forests, which had decreases of 8.92 and $8.69 \%$, respectively (Table 4). Moreover, there were miscellaneous areas, which could be urbanised surrounding the university.

\subsection{Changes in Built-Up Areas}

Table 5 lists the results of the built-up extraction. The overall accuracies of land-use classification for 2002 and 2019, as determined by the field survey, were 86.55 and $90.76 \%$ for RF classification, respectively, and 76.47 and $82.35 \%$ for OBIA, respectively. According to the RF classification, built-up areas covered $3.04 \mathrm{~km}^{2}(11.20 \%)$ in 2002 and $7.21 \mathrm{~km}^{2}(26.54 \%)$ in 2019 ; this equates to an increase of $15.34 \%$. Non-built-up areas decreased from $24.13 \mathrm{~km}^{2}(88.80 \%)$ in 2002 to $19.96 \mathrm{~km}^{2}$ $(73.46 \%)$ in 2019 , a decrease of $14.62 \%$. Figure 4 shows the land-use extraction results regarding built-up areas.

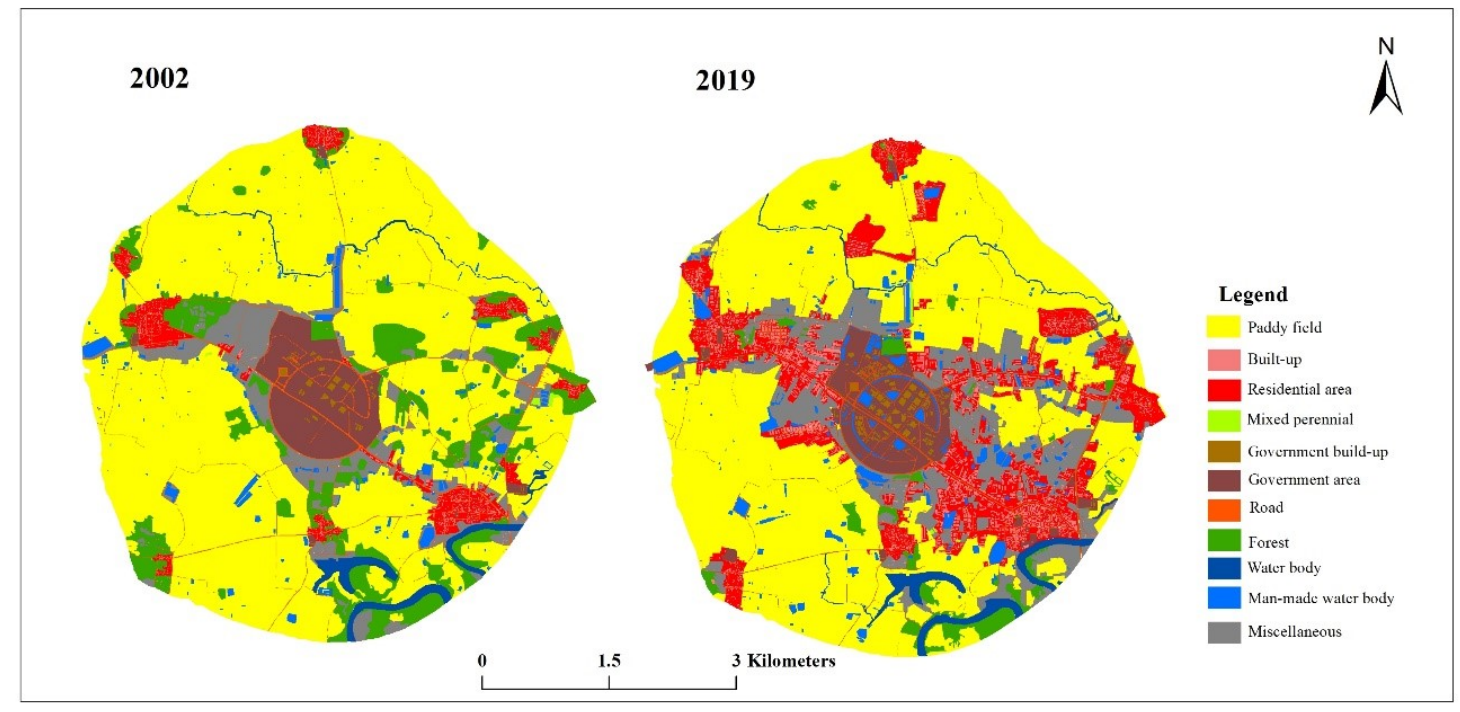

Figure 3: Land-use at Mahasarakham University based on visual image interpretation for 2002 and 2019 
Table 3: Land-use changes identified using visual image interpretation (VII) from 2002 to 2019

\begin{tabular}{|c|c|c|c|c|c|c|c|c|c|}
\hline Year & \multicolumn{4}{|c|}{2002} & \multicolumn{4}{|c|}{2019} & 2002-2019 \\
\hline Classified data (LU) & $\begin{array}{l}\text { Area } \\
\left(\mathbf{k m}^{2}\right)\end{array}$ & $\%$ & $\begin{array}{l}\text { PA } \\
(\%)\end{array}$ & $\begin{array}{l}\text { UA } \\
(\%)\end{array}$ & $\begin{array}{l}\text { Area } \\
\left(\mathbf{k m}^{2}\right)\end{array}$ & $\%$ & $\begin{array}{l}\text { PA } \\
(\%)\end{array}$ & $\begin{array}{l}\text { UA } \\
(\%)\end{array}$ & $\begin{array}{c}\text { LU Area } \\
(\%)+/-\end{array}$ \\
\hline Paddy field & 17.59 & 55.96 & 100 & 95 & 14.78 & 47.04 & 100 & 96 & -8.92 \\
\hline Mixed perennial area & 0.04 & 0.13 & 100 & 100 & 0.05 & 0.17 & 100 & 100 & +0.04 \\
\hline Built-up area & 0.23 & 0.74 & 100 & 100 & 2.54 & 8.09 & 75 & 100 & +7.35 \\
\hline Residential area & 1.12 & 3.57 & 100 & 100 & 4.52 & 14.38 & 94 & 100 & +10.81 \\
\hline Government build-up & 0.08 & 0.25 & 100 & 100 & 0.40 & 1.26 & 100 & 100 & +1.01 \\
\hline Government area & 1.79 & 5.68 & 100 & 100 & 1.91 & 6.09 & 100 & 100 & +0.41 \\
\hline Road & 0.58 & 1.84 & 100 & 100 & 0.78 & 2.48 & 100 & 100 & +0.64 \\
\hline Forest & 3.67 & 11.68 & 86 & 100 & 0.94 & 2.99 & 100 & 98 & -8.69 \\
\hline Water body & 0.67 & 1.74 & 88 & 100 & 0.97 & 3.10 & 100 & 100 & +1.36 \\
\hline Man-made water body & 0.55 & 2.15 & 100 & 88 & 0.57 & 1.81 & 100 & 100 & -0.34 \\
\hline Miscellaneous & 5.11 & 16.25 & 91 & 100 & 3.96 & 12.59 & 81 & 100 & -3.66 \\
\hline Sum & 31.44 & 100 & 96.81 & 98.45 & 31.44 & 100 & 95.45 & 99.45 & \\
\hline Overall accuracy & \multicolumn{4}{|c|}{97} & \multicolumn{4}{|c|}{97.5} & \\
\hline Kappa & \multicolumn{4}{|c|}{1} & \multicolumn{4}{|c|}{1} & \\
\hline
\end{tabular}

Table 4: Land-use changes from 2002 to $2019\left(\mathrm{~km}^{2}\right)$ determined via the change detection method

\begin{tabular}{|c|c|c|c|c|c|c|c|c|c|c|c|c|c|}
\hline & & \multicolumn{12}{|c|}{ Land Use $2019\left(\mathrm{~km}^{2}\right)$} \\
\hline & & A100 & A301 & U204 & U205 & U300 & U301 & U405 & F201 & W201 & W101 & M405 & sum \\
\hline \multirow{22}{*}{ 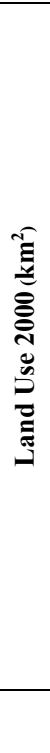 } & $\begin{array}{l}\mathrm{A} 100 \\
(\%)\end{array}$ & $\begin{array}{c}13.83 \\
44\end{array}$ & $\begin{array}{c}0.01 \\
0\end{array}$ & $\begin{array}{c}0.44 \\
1\end{array}$ & $\begin{array}{c}1.66 \\
5\end{array}$ & $\begin{array}{c}0.00 \\
0\end{array}$ & $\begin{array}{c}0.00 \\
0\end{array}$ & $\begin{array}{c}0.09 \\
0\end{array}$ & $\begin{array}{c}0.07 \\
2\end{array}$ & $\begin{array}{c}0.41 \\
1\end{array}$ & $\begin{array}{c}0.07 \\
0\end{array}$ & $\begin{array}{c}1.45 \\
5\end{array}$ & $\begin{array}{c}18.03 \\
57\end{array}$ \\
\hline & A301 & 0.00 & 0.02 & 0.00 & 0.00 & 0.00 & 0.02 & 0.00 & 0.00 & 0.00 & 0.07 & 0.02 & 0.13 \\
\hline & U204 & 0.00 & 0.00 & 0.13 & 0.22 & 0.00 & 0.01 & 0.00 & 0.00 & 0.00 & 0.00 & 0.01 & 0.37 \\
\hline & $(\%)$ & 0 & 0 & 0 & 1 & 0 & 0 & 0 & 1 & 0 & 0 & 0 & 1 \\
\hline & U205 & 0.01 & 0.00 & 0.37 & 1.10 & 0.00 & 0.05 & 0.00 & 0.01 & 0.00 & 0.00 & 0.01 & 1.18 \\
\hline & (\%) & 0 & 0 & 1 & 3 & 0 & 0 & 0 & 3 & 0 & 0 & 0 & 5 \\
\hline & U300 & 0.00 & 0.00 & 0.00 & 0.00 & 0.08 & 0.08 & 0.00 & 0.00 & 0.00 & 0.00 & 0.00 & 0.16 \\
\hline & $(\%)$ & 0 & 0 & 0 & 0 & 0 & 0 & 0 & 0 & 0 & 0 & 0 & 1 \\
\hline & U301 & 0.00 & 0.02 & 0.00 & 0.00 & 0.02 & 1.79 & 0.14 & 0.25 & 0.17 & 0.00 & 0.07 & 2.46 \\
\hline & $(\%)$ & 0 & 0 & 0 & 0 & 0 & 6 & 0 & 1 & 1 & 0 & 0 & 8 \\
\hline & U405 & 0.00 & 0.00 & 0.00 & 0.00 & 0.00 & 0.10 & 0.57 & 0.00 & 0.00 & 0.00 & 0.01 & 0.68 \\
\hline & $(\%)$ & 0 & 0 & 0 & 0 & 0 & 0 & 2 & 0 & 0 & 0 & 0 & 2 \\
\hline & F201 & 0.51 & 0.00 & 0.18 & 0.95 & 0.06 & 0.73 & 0.07 & 0.77 & 0.06 & 0.02 & 0.88 & 4.05 \\
\hline & $(\%)$ & 2 & 0 & 1 & 3 & 0 & 2 & 0 & 2 & 0 & 0 & 0 & 13 \\
\hline & W201 & 0.14 & 0.00 & 0.02 & 0.08 & 0.00 & 0.10 & 0.00 & 0.01 & 0.35 & 0.00 & 0.08 & 0.78 \\
\hline & (\%) & 0 & 0 & 0 & 0 & 0 & 0 & 0 & 0 & 1 & 0 & 0 & 2 \\
\hline & W101 & 0.05 & 0.00 & 0.00 & 0.00 & 0.00 & 0.00 & 0.00 & 0.02 & 0.00 & 0.47 & 0.01 & 0.55 \\
\hline & $(\%)$ & 0 & 0 & 0 & 0 & 0 & 0 & 0 & 0 & 0 & 1 & 0 & 2 \\
\hline & M405 & 0.22 & 0.00 & 0.25 & 0.73 & 0.00 & 0.03 & 0.02 & 0.05 & 0.09 & 0.01 & 0.92 & 2.32 \\
\hline & $(\%)$ & 1 & 0 & 1 & 2 & 0 & 0 & 0 & 0 & 0 & 0 & 3 & 7 \\
\hline & Sum & 14.76 & 0.05 & 1.39 & 4.74 & 0.34 & 2.91 & 0.89 & 1.18 & 1.08 & 0.64 & 3.46 & 31.44 \\
\hline & $(\%)$ & 47 & 0 & 4 & 15 & 1 & 9 & 3 & 4 & 3 & 2 & 11 & 100 \\
\hline
\end{tabular}

A100-Paddy field, A301-Mixed perennial area, U204-Built-up area, U205-Residential area, U300-Government build-up, U301Government area, U405-Road, F201-Forest, W101-Waterbody, W201-Man-made water body, M405-Miscellaneous.

Table 5: Estimated total area of built-up land: 2002 and 2019

\begin{tabular}{|l|c|c|c|c|c|c|c|c|}
\hline Method & \multicolumn{4}{|c|}{ OBIA } & \multicolumn{4}{c|}{ RF } \\
\hline Year & 2002 & 2019 & & 2002 & & 2019 & \\
\hline LU (Area) & Area $\left(\mathrm{km}^{2}\right)$ & $\%$ & Area $\left(\mathrm{km}^{2}\right)$ & $\%$ & Area $\left(\mathrm{km}^{2}\right)$ & $\%$ & $\begin{array}{c}\text { Area } \\
\left(\mathrm{km}^{2}\right)\end{array}$ & $\%$ \\
\hline Built-up & 2.05 & 7.56 & 4.23 & 15.56 & 3.04 & 11.20 & 7.21 & 26.54 \\
\hline Non-built-up & 25.12 & 92.44 & 22.94 & 84.44 & 24.13 & 88.80 & 19.96 & 73.46 \\
\hline Sum & 27.17 & 100 & 27.17 & 100 & 27.17 & 100 & 27.17 & 100 \\
\hline Overall accuracy & \multicolumn{7}{|c|}{76.47} & \multicolumn{7}{|c|}{82.35} & \multicolumn{2}{c|}{86.55} & \multicolumn{2}{c|}{90.76} \\
\hline
\end{tabular}

The RF results were more accurate than the OBIA results, as measured using ground surveys and statistical approaches. In addition, the high levels of built-up areas identified via RF classification in the 2002 and 2019 maps were used to assess the population data. 


\subsection{Population Estimation}

Results of the population estimations from 2002 to 2019 were closely related to the VII analysis. In 2002 , most of the population was concentrated in the area surrounding the university and close to agricultural areas. In 2019, the population was concentrated in the residential and commercial districts near the university town. The nature of expansion led to the creation of a road to connect the university with the surrounding urban community, with a corresponding ribbon development, as shown in Figure 3. The efficiency evaluation of the point-, pixel-, and area-based methods used the $\mathrm{R}^{2}$ and RMSE indices with the actual population from 60 sample data in both years. Table 6 lists the results of the three methods of population estimation for the $\mathrm{R}^{2}$ and RMSE values. The population estimation reveals that the areabased method was efficient based on the $\mathrm{R}^{2}$ values ( 0.92 and 0.93 in 2002 and 2019, respectively). The area-based method underperformed and was an excellent means of rapidly predicting the population in areas with complex land use, as shown in Figure 5. Moreover, the linear regression analysis of the relationships among the land-use type, size of the built-up area, and population in 2002 and 2019 produced determination coefficients $\left(\mathrm{R}^{2}\right)$ ranging from $0.62-0.97$. In 2002 , the population was mostly dependent on the number of single rooms $\left(\mathrm{R}^{2}=\right.$ 0.97), which was similar to the number of houses $\left(\mathrm{R}^{2}=0.95\right)$. In 2019 , the population depended on the number of rooms in a row house $\left(\mathrm{R}^{2}=0.91\right)$, houses, hotels, and dormitories $\left(\mathrm{R}^{2}=0.84\right)$. The classification of land-use according to the size of the building and the population yielded appropriate spatial population projections, as shown in Figure 5. Considering the population of each grid using the point- and pixel-based methods, the $300 \mathrm{~m}^{2}$ grid area yielded the highest $\mathrm{R}^{2}$.

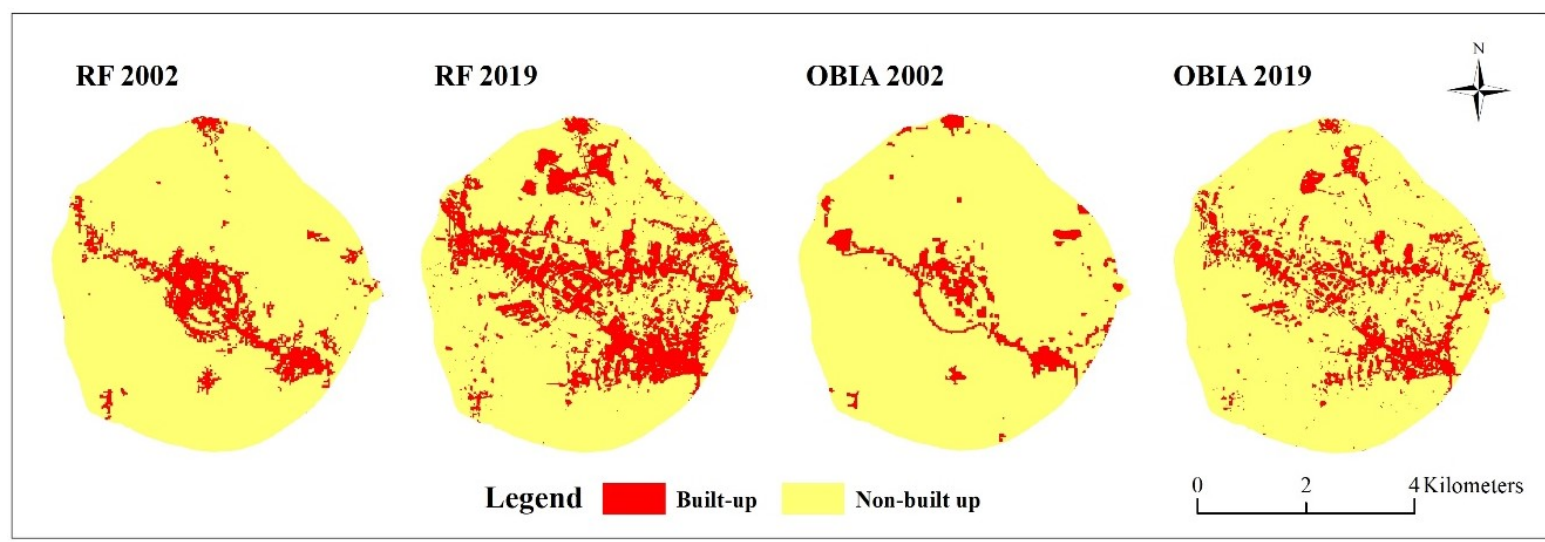

Figure 4: Built-up and non-built-up area extraction using RF and OBIA classification for 2002 and 2019

Table 6: Accuracy assessment results for the point-, pixel-, and area-based methods

\begin{tabular}{|l|c|c|c|c|c|c|}
\hline & \multicolumn{2}{|c|}{$\mathbf{2 0 0 2}$} & \multicolumn{2}{|c|}{$\mathbf{2 0 1 9}$} \\
\hline & $\begin{array}{c}\text { Population } \\
\text { estimation }\end{array}$ & $\mathbf{R}^{\mathbf{2}}$ & $\mathbf{R M S E}$ & $\begin{array}{c}\text { Population } \\
\text { estimation }\end{array}$ & $\mathbf{R}^{\mathbf{2}}$ & RMSE \\
\hline Point-based & & & & & & \\
\hline 50 & 6,638 & 0.91 & 4.96 & 49,601 & 0.90 & 18.26 \\
\hline 100 & 5,432 & 0.74 & 19.67 & 33,370 & 0.82 & 25.34 \\
\hline 200 & 7,038 & 0.91 & 29.52 & 45,097 & 0.91 & 40.47 \\
\hline 300 & 7,090 & 0.93 & 32.59 & 41,791 & 0.93 & 100.25 \\
\hline Pixel-based & & & & & & \\
\hline 50 & 15,270 & 0.75 & 5.51 & 93,546 & 0.79 & 19.43 \\
\hline 100 & 10,725 & 0.89 & 22.41 & 50,844 & 0.92 & 20.63 \\
\hline 200 & 23,273 & 0.74 & 125.68 & 39,306 & 0.94 & 88.25 \\
\hline 300 & 9,874 & 0.92 & 88.38 & 46,871 & 0.92 & 110.26 \\
\hline $\begin{array}{l}\text { Area-based } \\
\text { All built-up } \\
\text { type }\end{array}$ & 7,967 & 0.92 & 2.29 & 42,440 & 0.93 & 2.61 \\
\hline
\end{tabular}

Population in 2002: 7,558; and population in 2019: 43,406 (Source: Department of Provincial Administration, 2019). 


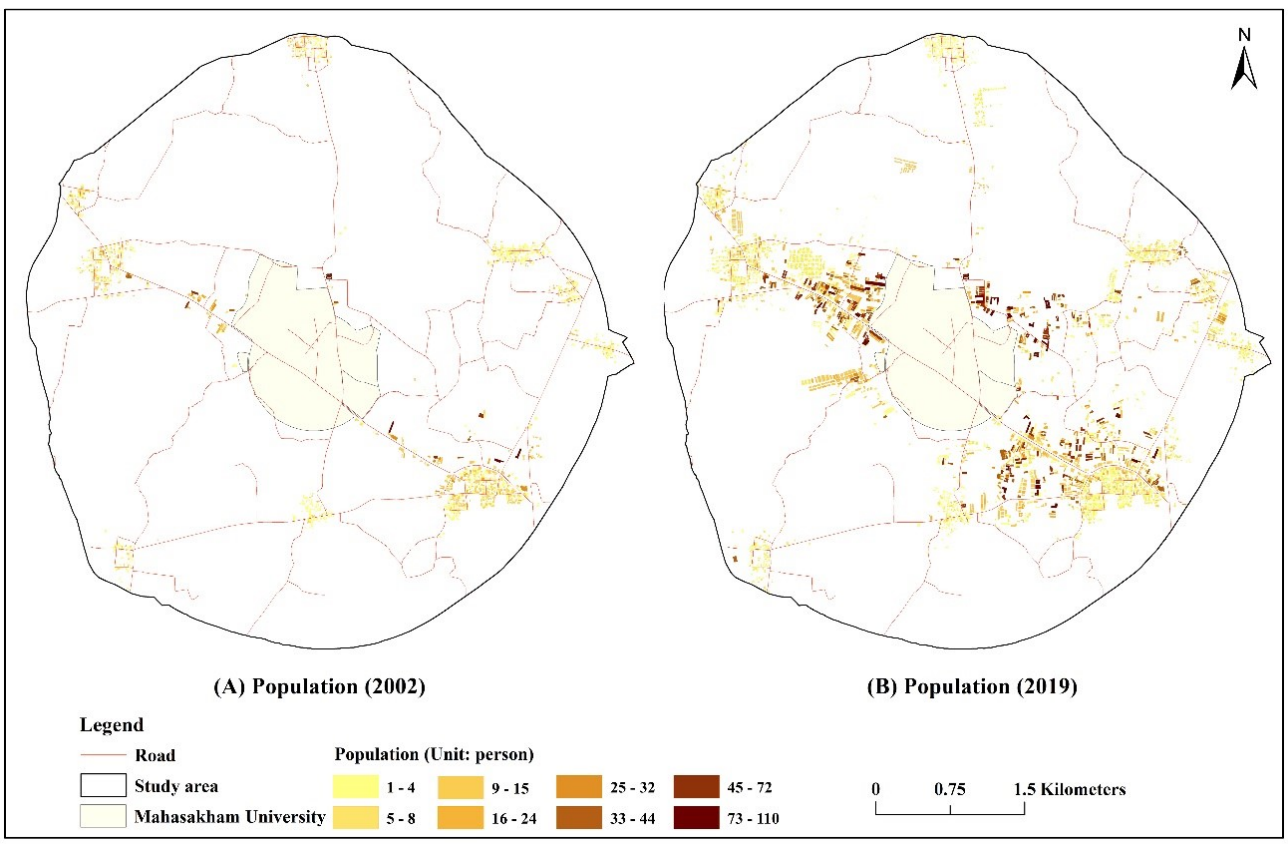

Figure 5: Population estimation based on the area-based approach for (A) 2002 and (B) 2019

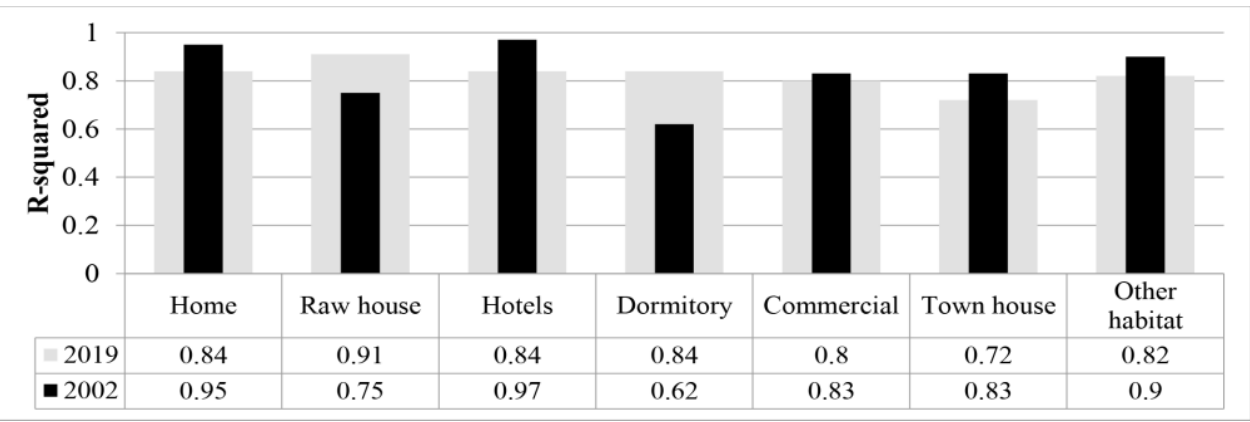

Figure 6: Correlation coefficients $\left(\mathrm{R}^{2}\right.$ of the land-use classification according to the size of the building) for 2002 and 2019

The $\mathrm{R}^{2}$ values using the point-based approach were 0.92 in 2002 and 0.93 in 2019, and the RMSEs were 32.59 in 2002 and 100.25 in 2019 . To compare the methods, the point-based approach was more satisfactory than the pixel-based approach due to the lower RMSE. In addition to our experience, this technique appeared to provide a valuable estimation of the population in a rural area using freely available remote sensing data (i.e., Google Earth and Open Street Map imagery) (Patel et al., 2015).

\section{Discussion}

Overpopulation is a major global issue, particularly in developing countries. Advanced techniques for estimating populations and land-use changes using remote sensing images may provide more rapid estimations than those produced through censuses, which can therefore be used to identify policies and plans for further development. Mahasarakham University is a centre of education in north-eastern Thailand and has experienced rapid and continuous growth since the implementation of a 'Ministry of Education' policy aimed at expanding educational opportunities (Keawnimit et al., 2016).

The economic returns of operating service businesses are evidently higher than those of farming (Figure 7). Local residents earn their income by selling land, and a few have converted the vending of rice paddies into a residential business. As a result, land-use development has supported the growth of the university. This study identified a new land-use pattern called 'uniurbanisation,' which refers to the rapid expansion of an urban area in the form of urbanised clusters around a university. 

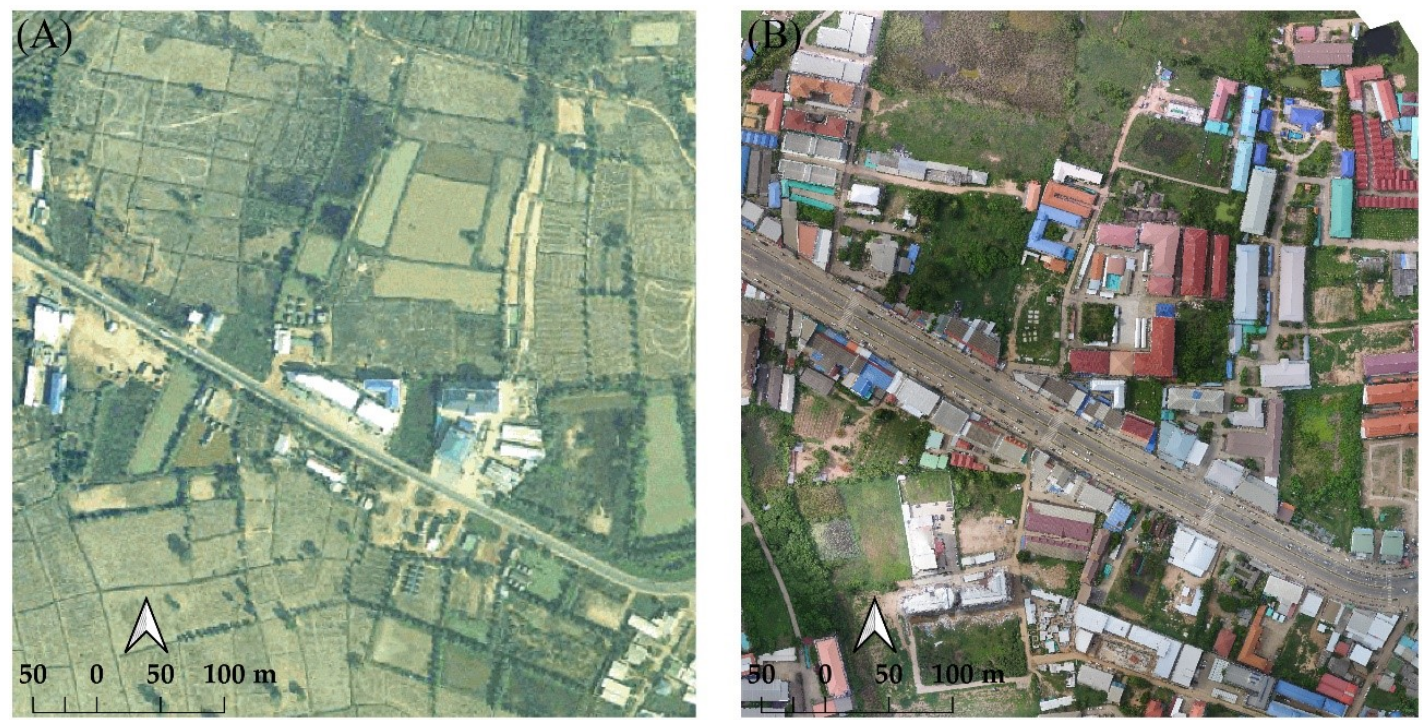

Figure 7: (A) Aerial photography acquired in 2002 by the Royal Thai Survey Department and (B) UAV image taken on 23 May 2019, using a DJI Phantom 3 Professional

The university serves as a key centre that attracts students and others to live adjacent to the university. This land-use pattern is more apparent around universities in Southeast Asian countries and not around universities in Europe, the U.S.A., and Australia. Thus, we strongly recommend that studies on the land-use changes associated with other Asian universities should be conducted in the future. Applying the VII method using land-use maps is highly accurate and efficient, involving user knowledge, the possibility of verification via field surveys, and high-resolution images. For effective image interpretation, an algorithm that improves image contrast is essential (Alahmadi et al., 2013, Som-ard et al., 2018 and Svatonova, 2016). The RF method is sufficiently flexible in identifying built-up areas to allow the input of multi-sourced data (Chen et al., 2017, Ma et al., 2017, Pesaresi et al., 2016 and Sun et al., 2017). The use of Sentinel-2A images is highly effective for mapping built-up areas, and the utilisation of these images for mapping other urban sites is recommended (Ettehadi et al., 2019). However, this study only used images taken on a single date to extract built-up areas. The misclassification of built-up areas and miscellaneous regions occurred due to the presence of reflectance spectral features, which had similar signature information and pixel values that overlapped with those of the NBDI index (Guha et al., 2018). These issues can lead to an inaccurate extraction of builtup areas. Further, multi-temporal image and geospatial data are necessary to allow the accurate classification of built-up areas in complex land-use contexts. Moreover, OBIA and RF classifiers must be well integrated to successfully identify built-up areas and overcome the limitations (i.e., high generalisation error and OOB error) discussed in Pflugmacher et al., (2019). The point-, area-, and pixel-based methods produced different population estimates based on land-use and population data acquired through a field survey. The sizes of the residential areas relative to the average population in each built-up type were different. This study found that the area-based estimation technique was highly accurate and can be used with confidence because this method measures the average population per residence based on the building type according to land-use maps and field surveys. The identified structures mostly included detached houses, row houses, hotels, dormitories, commercial buildings, and townhouses. Alahmadi et al., (2014) suggested that classifying built-up areas within different structure categories can improve the accuracy of population estimates; this study was based on this idea and aimed to estimate the population of each built-up area. Population calculated via an area-based approach yields different results from those estimated via other approaches. The use of significantly high-spatial resolution imagery considerably improved the accuracy of the estimates (Alahmadi et al., 2013 and 2014, Dong et al., 2010, Guo et al., 2017 and Mossoux et al., 2018). The estimated population of the built-up area type, identified using the VII method, was in good agreement with the actual population (Kaimaris and Patias, 2016). This result was verified and coincides with the results of 
previous studies (Guo et al., 2017 and Saberifar, 2013).

Meanwhile, the highest average $\mathrm{R}^{2}$ and RMSE values for both years indicated that the model provided an acceptable level of accuracy compared to population data obtained from surveys and interviews. A similar area-based approach was also found to be effective for population estimation in a complex land-use area around the university of the Philippines (Galeon, 2008). Some limitations concerning the use of land-use maps to estimate population were identified, which led to inaccuracies in the estimated population (Galeon, 2008, Kaimaris and Patias, 2016 and Deng et al., 2010). In contrast, aerial remote sensing data (i.e., UAV images) provided high-quality land information for the visual interpretation of built-up structures in this study. Simple linear regression provided highly accurate population estimations. Therefore, we suggest applying UAV images for rapid, reliable, and cost-effective population estimates in other areas. Compared to the area-based approach, both the pixel- and point-based estimation methods resulted in values that were more similar to those obtained through the field survey. A grid size of 200-300 $\mathrm{m}^{2}$ was satisfactory for estimation and provided results that were even more accurate than those using the pixel-based method. The grid-based approach used the exact location of built-up areas from the VII method and determined groups of building types based on grids. This approach has proven effective for population estimation under complex land-use situations. Thus, this method and grid scales are promising for applications at other urban sites and should be validated under different land-use patterns. However, population estimation using the pixel-based method was also relatively accurate and should be conducted using a grid size of $250-300 \mathrm{~m}^{2}$, which is a suitable scale for urban land use (Ye et al., 2019). The pixel-based approach was less accurate because of the misclassification of built-up areas. The pixel-based method is faster and more accurate, and it may be useful to analyse similar build-up types on a larger scale (in conjunction with ground surveys) to reduce estimation discrepancies. Moreover, the campus area targeted in this study represents a variety of human activities. Applying this approach to communities of different sizes may yield different results, thereby introducing error. Therefore, the pixel-based approach may provide better estimation accuracy in large communities (Karume et al., 2017, Sun et al., 2016 and Ye et al., 2019).

An accurate assessment of the population size is key for developing social and economic policies (Saberifar, 2013). Population estimates have proven beneficial for policy planning in both public and private-sector organisations, including those focused on economic, social, and public health-related issues (Karume et al., 2017 and Xie et al., 2015). According to survey-based activity data, area-based methods can be applied to estimate the populations of university towns in both Thailand and other Southeast Asian countries with similar urban cluster patterns. Additionally, they should be applied to city growth rates to generate estimates that will support government agencies that currently lack annual population data. The area-based approach is rapid and inexpensive, and is therefore ideal for providing population estimates in a timely manner. Furthermore, using detailed satellite images in comparison with spatial statistical analysis and geoweighted regression analysis techniques can help to further increase the accuracy of population estimations. Sentinel-2A images can be effectively applied for population estimation in other urban areas and university towns in Southeast Asian countries. Moreover, automated approaches, such as OBIA and RF classification, should be applied to identify building types based on roof characteristics in future studies. This approach may facilitate rapid classification and simple building identification at a large scale. These techniques allow population estimations over diverse spatial areas and can be applied in areas with diverse geographical and social characteristics.

\section{Conclusions}

Land-use maps and land-use change based on the VII method from 2002 to 2019 showed that there was population growth in the study area surrounding Mahasarakham University, which is considered an important factor that influences land-use changes. There was also a reduction in the paddy-field area, together with an increase in built-up and residential areas. The RF method for the extraction of information on built-up areas using the Landsat-7 ETM+ in 2002 and Sentinel-2A MSI in 2019 was more accurate than the OBIA method due to the optimal classification algorithm in RF. The RF classifier approach detects the generalization error (OOB) and has no overfitting problem for the resulting model estimates. Moreover, multi-spectral image data can be imported to measure features ranked by the MDA approach. Although the study area has a complex pattern of land use, the areabased method for population estimation and landuse change analyses were more accurate than the point- and pixel-based methods. Therefore, the methods described in this study are useful for spatial decision-making through the provision of rapid costeffective census data collection in a sub-district 
municipality. Specifically, the proposed methods can provide a basis for land-use planning surrounding university towns. Such development requires cooperation among the university, local administrative organizations, and local community to manage zoning areas and activities. Future research objectives should include the development of statistical techniques, along with aerial remote sensing data, which can be used to determine the relationship between land-use types and population estimations.

\section{References}

Alahmadi, M., Atkinson, P. and Martin, D., 2013, Estimating the Spatial Distribution of the Population of Riyadh, Saudi Arabia Using Remotely Sensed Built Land Cover and Height Data. Computers, Environment and Urban Systems, Vol. 41, 167-176.

Alahmadi, M., Atkinson, P. M. and Martin, D., 2014, A Comparison of Small-Area Population Estimation Techniques Using Built-Area and Height Data, Riyadh, Saudi Arabia. IEEE Journal of Selected Topics in Applied Earth Observations and Remote Sensing, Vol. 9, 19591969.

Bai, Z., Wang, J., Wang, M., Gao, M. and Sun, J., 2018, Accuracy Assessment of Multi-Source Gridded Population Distribution Datasets in China. Sustainability, Vol. 10, 1363.

Bangira, T., Alfieri, S. M., Menenti, M., \& van Niekerk, A., 2019, Comparing Thresholding with Machine Learning Classifiers for Mapping Complex Water. Remote Sensing, Vol. 11, 1-15.

Batista e Silva, F., Gallego, J. and Lavalle, C., 2013, A High-Resolution Population Grid Map for Europe. Journal of Maps, Vol. 9(1), 16-28.

Blaschke, T., 2010, Object Based Image Analysis for Remote Sensing. ISPRS Journal of Photogrammetric Remote Sensing, Vol. 65, 216.

Breiman, L., 2001, Random Forests. Machine Learning, Vol. 45, 5-32.

Brooner, W., 1976, Land Use Map Accuracy Criteria. Photogrammetric Engineering and Remote Sensing, Vol. 46, 671-677.

Chaichakan, C., Nopparak, P., Khampeng, D., Prommarin, N., Khadthipong, P., Pongpipat, N. S. and Wasawan, K., 2017, Urbanization in the Communities Surrounding the University of Phayao: The Case of Maeka Sub-district, Phayao Province. Area Based Development Research Journal, Vol. 9(3), 178-190.

Chen, W., Xie, X., Wang, J., Pradhan, B., Hong, H., Bui, D. T. and Ma, J., 2017, A Comparative
Study of Logistic Model Tree, Random Forest, and Classification and Regression Tree Models for Spatial Prediction of Landslide Susceptibility. Catena, Vol. 151, 147-160.

Congalton, R. G. and Green, K., 1999, Assessing the Accuracy of Remotely Sensed Data: Principles and Practices. Boca Raton, FL: Lewis Publishers.

Cutler, A., Cutler, D. R. and Stevens, J. R., 2012, Random Forests. In Ensemble Machine Learning, Boston, MA Springer. 157-175.

Department of Provincial Administration. Official Statistics Registration Systems, 2019, http://stat.bora.dopa.go.th/stat/statnew/statMenu/ newStat/home.php. Accessed 18 November 2019.

Deng, C., Wu, C. and Wang, L., 2010, Improving the Housing-Unit Method for Small-Area Population Estimation Using Remote-Sensing and GIS Information. International Journal of Remote Sensing, Vol. 31, 5673-5688.

Dong, P., Ramesh, S. and Nepali, A., 2010, Evaluation of Small-Area Population Estimation Using LiDAR, Landsat TM and Parcel Data. International Journal of Remote Sensing, Vol. 31, 5571-5586.

Ettehadi Osgouei, P., Kaya, S., Sertel, E. and Alganci, U., 2019, Separating Built-Up Areas from Bare Land in Mediterranean Cities Using Sentinel-2A a Imagery. Remote Sensing, Vol. $11,1-24$.

Galeon, F., 2008, Estimation of Population in Informal Settlement Communities Using High Resolution Satellite Image. In XXI ISPRS Congress, Commission IV. Beijing, Vol. 37, Part No. B4, 1377-1381.

Goodchild, M. F., Anselin, L. and Deichmann, U., 1993, A Framework for the Areal Interpolation of Socioeconomic Data. Environment and planning A, Vol. 25(3), 383-397.

Guha, S., Govil, H., Dey, A. and Gill, N., 2018, Analytical Study of Land Surface Temperature with NDVI and NDBI Using Landsat 8 OLI and TIRS Data in Florence and Naples City, Italy. European Journal of Remote Sensing, Vol. 51, 667-678.

Guo, H., Cao, K. and Wang, P., 2017, Population Estimation in Singapore Based on Remote Sensing and Open Data. International Archives of Photogrammetric Remote Sensing \& Spatial Information Science, Vol. 42, 1181-1187.

Guo, X., Shao, Q., Li, Y., Wang, Y., Wang, D., Liu, J., Fan, J. and Yang, F., 2018, Application of UAV Remote Sensing for a Population Census of Large Wild Herbivores-Taking the Headwater 
Region of the Yellow River as an Example. Remote Sensing, Vol. 10, 1-15.

Hu, T., Yang, J., Li, X. and Gong, P., 2016, Mapping Urban Land Use by Using Landsat Images and Open Social Data. Remote Sensing, Vol. 8, 1-18.

Hua, L., Man, W., Wang, Q. and Zhao, X., 2012, A New Decision Tree Classification Approach for Extracting Urban Land from Landsat TM in a Coastal City, China. Fourth International Symposium on Information Science and Engineering, Shanghai, China.

Immitzer, M., Vuolo, F. and Atzberger, C., 2016, First Experience with Sentinel-2A Data for Crop and Tree Species Classifications in Central Europe. Remote Sensing, Vol. 8, 1-17.

Immitzer, M., Neuwirth, M., Böck, S., Brenner, H., Vuolo, F. and Atzberger, C., 2019, Optimal Input Features for Tree Species Classification in Central Europe Based on Multi-Temporal Sentinel-2A Data. Remote Sensing, Vol. 11, 123.

Johnson, B. and Xie, Z., 2013, Classifying a High Resolution Image of an Urban Area Using Super-Object Information. ISPRS Journal of Photogrammetric Remote Sensing, Vol. 83, 4049.

Kaimaris, D. and Patias, P., 2016, Population Estimation in An Urban Area with Remote Sensing and Geographical Information Systems. International Journal of Advances in Remote Sensing. GIS, Vol. 5, 1795-1812.

Karume, K., Schmidt, C., Kundert, K., Bagula, M., Safina, B., Schomacker, R. and Karume, N., 2017, Use of Remote Sensing for Population Number Determination. Open Access Journal of Science and Technology, Vol. 5, 1-9.

Kavzoglu, T. and Yildiz, M., 2014, Parameter-Based Performance Analysis of Object-Based Image Analysis Using Aerial and Quikbird-2 Images. ISPRS Annals Photogrammetry, Remote Sensing, \& Spatial Information Science, Vol. 2, 31-37.

Keawnimit, K., PattiyaThani, S. and Jumpafad, V., 2016, Reason Related to the Decision to Study for a Bachelor's Degree in the Faculty of Education, Mahasarakham University. Journal of Educational Measurement Mahasarakham University, Vol. 22, 3-15.

Kumar, M., Singh, R. B., Pravesh, R., Kumar, P., Tripathi, D. K. and Sahu, N., 2018, Urban Growth Dynamics and Modelling Using Remote Sensing Data and Multivariate Statistical Techniques. CURRENT SCIENCE, Vol. 114(10).
Land Development Department, 1977, Land-Use Map 1977. In Ministry of Agriculture and Cooperatives. Bangkok, Thailand.

Land Development Department, 2016, Land-Use Map 2016. In Ministry of Agriculture and Cooperatives. Bangkok, Thailand.

Liaw, A. and Wiener, M., 2002, Classification and Regression by Random Forest. $R$ News, Vol. 2(3), 18-22.

Lloyd, C. T., Sorichetta, A. and Tatem, A. J., 2017, High Resolution Global Gridded Data for Use in Population Studies. Scientific Data, Vol. 4(1), 117.

Lu, Z., Im, J., Quackenbush, L. and Halligan, K., 2010, Population Estimation Based on MultiSensor Data Fusion. International Journal of Remote Sensing, Vol. 31, 5587-5604.

Lu, D., Li, G. and Moran, E., 2014, Current Situation and Needs of Change Detection Techniques. International Journal of Image Data Fusion, Vol. 5, 13-38.

Ma, L., Li, M., Ma, X., Cheng, L., Du, P. and Liu, Y., 2017, A Review of Supervised Object-Based Land-Cover Image Classification. ISPRS Journal of Photogrammetric Remote Sensing, Vol. 130, 277-293.

Mahasarakham University, 2019, Data Student Study in Higher Education in 1995-2020. Division of Planning Mahasarakham University.

Mossoux, S., Kervyn, M., Soulé, H. and Canters, F., 2018, Mapping Population Distribution from High Resolution Remotely Sensed Imagery in a Data Poor Setting. Remote Sensing, Vol. 10, 119.

Munyati, C., 2017, The Potential for Integrating Sentinel 2 MSI with SPOT 5 HRG and Landsat 8 OLI Imagery for Monitoring Semi-Arid Savannah Woody Cover. International Journal of Remote Sensing, Vol. 38, 4888-4913.

Office of the Nation Economic and Social Development Board, 2007, Population Projections for Thailand 2000-2030; Bangkok.

Páez, A. and Scott, D. M., 2004, Spatial Statistics for Urban Analysis: A Review of Techniques with Examples. GeoJournal, Vol. 61(1), 53-67.

Patel, N. N., Angiuli, E., Gamba, P., Gaughan, A., Lisini, G., Stevens, F. R. and Trianni, G., 2015, Multitemporal Settlement and Population Mapping from Landsat Using Google Earth Engine. International Journal of Applied Earth Observation and Geoinformation, Vol. 35, 199208.

Pesaresi, M., Corbane, C., Julea, A., Florczyk, A. J., Syrris, V. and Soille, P., 2016, Assessment of the Added-Value of Sentinel-2A for Detecting Built-Up Areas. Remote Sensing, Vol. 8, 1-18. 
Pflugmacher, D., Rabe, A., Peters, M. and Hostert, P., 2019, Mapping pan-European Land Cover Using Landsat Spectral-Temporal Metrics and the European LUCAS survey. Remote Sensing of Environment, Vol. 221, 583-595.

Phiri, D. and Morgenroth, J., 2017, Developments in Landsat Land Cover Classification Methods: A Review. Remote Sensing, Vol. 9(9), 1-25.

Prasanchum, H. and Kangrang, A., 2017, Analyses of Climate and Land Use Changes Impact on Runoff Characteristics for Multi-Purpose Reservoir System. The 4th EIT International Conference on Water Resources Engineering, Chonburi, Thailand. JICA, Chonburi, Thailand. 1-16.

Prasartkul, P., Rittirong, J. and Kaikeaw, S., 2016, Household Projection of the Thai Population during 2010-2020 (in Thai). A Journal of Thai Population Association, Vol. 4 (2), 45-49.

Reibel, M. and Agrawal, A., 2007, Areal Interpolation of Population Counts Using PreClassified Land Cover Data. Population Research and Policy Review, Vol. 26(5-6), 619633.

Saberifar, R., 2013, Estimation of Urban Population by Remote Sensing Data. Journal of Emerging Trends in Economics and Management Science, Vol. 4, 565-569.

Silva, M. R. S., Eger, R. A., Rosenfeldt, Y. A. Z. and Loch, C., 2018, Testing DJI Phantom 4 Pro for Urban Georeferencing. International Archives of Photogrammetry, Remote Sensing, \& Spatial Information Science, Vol. 42, 407-411.

Som-ard, J., Suwanlee, S. R., Bunchai, P. and Aemaot, B., 2018, Predicting Land-Use Change from Construction at Mahasarakham Campus. Journal of Humanities and Social Sciences, Mahasarakram University, Vol. 37, 141-156.

Stevens, F. R., Gaughan, A. E., Linard, C. and Tatem, A. J., 2015, Disaggregating Census Data for Population Mapping Using Random Forests with Remotely-Sensed and Ancillary Data. PloS One, Vol. 10(2), 1-22

Stöcker, C., Nex, F., Koeva, M. and Gerke, M., 2019, UAV-Based Cadastral Mapping: An Assessment of the Impact of Flight Parameters and Ground Truth Measurements on the Absolute Accuracy of Derived Orthoimages. International Archives of the Photogrammetry, Remote Sensing \& Spatial Information Sciences. 613-617.

Sun, L., Wei, J., Duan, D., Guo, Y., Yang, D., Jia, C. and Mi, X. T., 2016, Impact of Land-Use and Land-Cover Change on Urban Air Quality in Representative Cities of China. Journal of
Atmospheric and Solar-Terrestrial Physics, Vol. 142, 43-54.

Sun, X., Lin, X., Shen, S. and Hu, Z., 2017, HighResolution Remote Sensing Data Classification Over Urban Areas Using Random Forest Ensemble and Fully Connected Conditional Random Field. ISPRS International Journal of Geo-Information, Vol. 6(8), 1-26.

Suwanlee, S. R. and Som-ard, J., 2020, Spatial Interaction Effect of Population Density Patterns in Sub-Districts of Northeastern Thailand. ISPRS International Journal of Geo-Information, Vol. 9(9), 1-15.

Svatonova, H., 2016, Analysis of Visual Interpretation of Satellite Data. International Archives of Photogrammetry, Remote Sensing, \& Spatial Information Science, Vol. 41, 675-681.

Wayumba, R., Mwangi, P. and Chege, P., 2017, Application of Unmanned Aerial Vehicles in Improving Land Registration in Kenya. International Journal of Research in Engineering \& Science, Vol. 5, 5-11.

Wu, S. S., Qiu, X. and Wang, L., 2005, Population Estimation Methods in GIS and Remote Sensing: A Review. GIScience \& Remote Sensing, Vol. 42(1), 80-96.

Xie, Y., Weng, A. and Weng, Q., 2015, Population Estimation of Urban Residential Communities Using Remotely Sensed Morphologic Data. IEEE Geoscience Remote Sensing Letters, Vol. 12(5), 1111-1115.

Yang, Z. and He, X., 2010, Automatic Extraction of Urban Land-Use Information from Remote Sensing Images Based on Improved NDBI Method. Journal of Hohai University of Natural Sciences, Vol. 38(2), 181-184.

Ye, T., Zhao, N., Yang, X., Ouyang, Z., Liu, X., Chen, Q. and Li, Z., 2019, Improved Population Mapping for China Using Remotely Sensed and Points-of-Interest Data Within a Random Forests Model. Science of the Total Environment, Vol. 658, 936-946.

Zha, Y., Gao, J. and Ni, S., 2003, Use of Normalized Difference Built-Up Index in Automatically Mapping Urban Areas from TM Imagery. International Journal of Remote Sensing, Vol. 24(3), 583-594.

Zhu, Z., Fu, Y., Woodcock, C. E., Olofsson, P., Vogelmann, J. E., Holden, C. and Yu, Y., 2016, Including Land Cover Change in Analysis of Greenness Trends Using all Available Landsat 5, 7, and 8 Images: A Case Study from Guangzhou, China (2000-2014). Remote Sensing of Environment, Vol. 185, 243-257. 